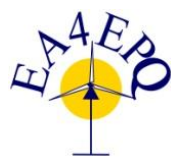

International Conference on Renewable Energies and Power Quality (ICREPQ'18)

Salamanca (Spain), $21^{\text {th }}$ to $23^{\text {rd }}$ March 2018

Renewable Energy and Power Quality. Tournal (RE\&PQJ)

ISSN 2172-038 X, No.16 April 2018

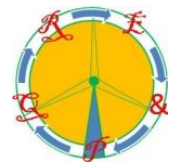

\title{
Dynamic Analysis of a Distribution Power Systems in Front of Two Strategy Control Applied To DFIG-Based Wind Turbines
}

\author{
F. R. Arduini ${ }^{1}$, G.J. Schäffer ${ }^{1}$, F. A. M. Moura' ${ }^{1}$ A. J. P. R. J' ${ }^{1}$ M. V. B. Mendonça ${ }^{1}$, P. H. O. Rezende ${ }^{1}$ and M. R. \\ M. Castillo ${ }^{1}$ \\ ${ }^{1}$ Universidade Federal do Triângulo Mineiro, Electrical Engineering Department, Uberaba- Minas Gerais, Brazil \\ fernando.arduini@yahoo.com.br, fabricio.moura@uftm.edu.br, IEEE Member.
}

\begin{abstract}
The connection of distributed generators in distribution systems of medium voltage or low voltage has been encouraged widely. Wind power generation in Brazil has been growing substantially in the last years. In this way, it is essential to investigate the dynamic behavior of this technology connected to the electrical grid. Among all power quality phenomenon, voltage sags are one of the main issues for the industry sector customers due to the damage caused to voltage sensitive devices largely employed in industrial applications. This paper aims to analyze the dynamic response of gridconnected doubly-fed induction generators subjected to an instantaneous voltage sag Type $A$, considering two rotor-side converter control topologies: Voltage Regulation and Reactive Power Regulation. The results will provide the reader a better comparative insight into the responses of these DFIG control topologies applied to a wind power system.
\end{abstract}

\section{Keywords}

Wind power, Doubly-Fed Induction Generator, Var Regulation, Voltage Regulation, Power Systems Dynamics.

\section{Introduction}

Demand for electricity in Brazil is growing rapidly, so the issue of water resource exploitation related to concerns about its scarcity is constantly cited as a key to changing the energy paradigm. The country has rich energy sources, enabling the deployment of distributed generation (DG) [1]. According to the Normative Resolution - ANEEL 482/2012 - the National Electric Energy Agency, Brazilian consumers can generate their own electricity from renewable sources and still provide a surplus for the distribution network [2]. Distributed generation is a power generation along or near an independent power consumer. This generation may be parallel or isolated with the network, increasing its guaranteed supply and being used in remote locations of large power plants, serving local consumers. In this regard, the electricity distribution system operator is faced with a more complex design operation planning, and maintenance of medium and low voltage networks because the power flow becomes dynamic, changing thus the fundamental characteristics of distribution networks, which is designed to operate radially [3]. To ensure the excellence and quality of electricity service delivery, it is necessary to study the interaction between DG systems with medium and low voltage networks.

Regarding the Brazilian electric sector, it can be said that the generation of electricity from wind has been increasing substantially. In 2016, there was an expansion of $2.014 \mathrm{GW}$ of this energy in the country, which placed Brazil in the 5th position in the world ranking of installed capacity. The country also occupied the new 9th position in the world ranking of the accumulated capacity of wind generation with $10.74 \mathrm{GW}$ installed [4].

It is noteworthy that there is no consensus, which means clear regulations of the best mode of operation of the DG when connected to the power distribution system (PDS), nor well-established criteria of protection, connection, product quality and dynamic for a safe and effective connection [56]. Thus, this article aims to evaluate the main impacts arising from the installation of medium-sized doubly-fed induction generators (DFIG) in the operation of distribution networks. Simulations are performed to investigate the dynamic behavior of the DFIG-based wind farm, considering two strategy control, when it is subjected to an instantaneous voltage sag. The results will be compared, and the main findings will be presented.

This paper is organized as follows: Section 2 describes the State-of-art, contributing relevant information on different aspects of the topic; Section 3 presents the model of the wind power farm and the various network components used in this work; Section 4 introduces the case studies and analyzes the system dynamics, and some conclusions are drawn in Section 5 .

\section{State-of-art}

Within wind power generation studies, there is in the literature a range of publications extending from qualitative and financial aspects of the use of wind generation technology to more technical aspects regarding its integration into the electric grid. It can be observed that the most studied wind generators are those with variable speed, specifically, the permanent-magnetic synchronous generator (PMSG) and doubly-fed induction generator (DFIG). Despite the rapid growth in the use of PMSGs, DFIGs still represent more than $70 \%$ of the installed wind power generation in the world [7]. References [8-9] address the qualitative aspects resulting from the wide use of this topology, such as: Ability to extract the maximum power from the primary source, regardless of wind intensity; Control flexibility offered by the generator; Support in the power system voltage and frequency stability; Reduction of mechanical stress in wind turbine components; Use of partial rated power electronic converters. In [10], significant contributions are added to the studies referring to DFIG modeling, more specifically, when it is under influence 
of voltage unbalance conditions in the electrical network. Reference [11] proposes an OPPT (Optimized Power Point Tracking) method that can smooth wind power injected into the grid, thereby reducing frequency fluctuations. In [12] it is presented issues about harmonic contents caused by the wind power system integration. Otherwise, reference [13] presents an approach for harmonic mitigation due to the wind power converter PWM switching.

In [14], methods are discussed to improve the wind turbine ability of fault ride-through (FRT). Such methods include employing a DC energy absorption circuit to limit DC link voltage, insertion of a protection circuit in the rotor side converter to limit short circuit current, and the use of Static Synchronous Compensator (STATCOM) to improve voltage profile at the terminals of the wind generator. Other approaches to FRT can be found in [15-16].

In this aspect, this paper aims to present the contributions and make a comparative analysis of the use of reactive power control (unit power factor), as well as terminal voltage control, in the face of common contingencies to electrical distribution systems, such as a three-phase instantaneous voltage sag.

\section{Power system modeling}

The study was conducted using SimPowerSystems platform, a Matlab/Simulink extension. In this study, the block Wind Turbine Doubly Fed Generator was adopted to simulate the complete wind power system, and other component models, provided by this extension, were used to represent the electrical network tested in this study. Basically, the system consists of six $1.5 \mathrm{MW}$ wind turbines connected to a $13.8 \mathrm{kV}$ medium voltage network. It must be highlighted that further information about the modeling used in this work can be found in reference [17]. The main wind power system elements and the electrical network are described below:

\section{A. Wind Turbine}

The mechanical power produced by a wind turbine is expressed by (1).

$$
P_{m}=C_{p}(\lambda, \beta) \cdot \frac{\rho A}{2} v_{\text {wind }}^{3}
$$

Where: Pm - Mechanical output power of the turbine (W); $\mathrm{C} p$ - Performance coefficient of the turbine; $p$ - Air density $\left(\mathrm{Kg} / \mathrm{m}^{3}\right) ; \mathrm{A}-$ Turbine swept area $\left(\mathrm{m}^{2}\right) ; v$ - Wind speed $(\mathrm{m} / \mathrm{s})$; $\lambda$ - Tip speed ratio; $\beta$ - Blade pitch angle (deg).

The maximum power from wind can be obtained when a wind turbine is operated at its optimum performance coefficient. This can be achieved by operating the turbine at a desired speed to obtain the optimal tip-speed ratio $\lambda \max$ [17]. The turbine power characteristics of this study are illustrated in Figure 1. The curves show the dependence of wind turbine on the wind speed and the turbine rotation speed. It is also shown, from point B to C, the optimum power curve that intersects every wind speed curve in the point where the power coefficient $\mathrm{C} p(\lambda, \beta)$ is maximum, for a pitch angle $\beta=0$. The utilized Simulink wind turbine model was a pitch controlled one. By changing the angle of attack of the blades, the pitch control system limits the output power generation to the rated power. The torque on the induction generator shaft is given by a wind turbine block in which a look-up table is applied to deduce the tracking characteristic $\mathrm{ABCD}$ curve, displayed in Figure 1. Until point $\mathrm{D}$, the pitch angle is kept constant at zero. Beyond point $\mathrm{D}$, when the wind speed is higher than the rated speed, $13.3 \mathrm{~m} / \mathrm{s}$, the pitch angle is proportional to the speed deviation from point D speed.

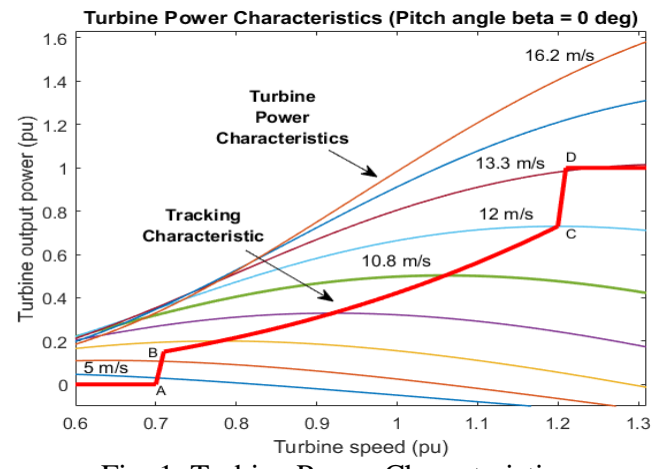

Fig. 1. Turbine Power Characteristics

\section{B. Doubly-fed induction generator (DFIG)}

The doubly-fed induction machine converts mechanical power generated by the wind turbine into electric power, which is transmitted to the grid by the stator and rotor windings. The DFIG's rotor windings are connected to an $\mathrm{AC} / \mathrm{DC} / \mathrm{AC}$ converter and its stator windings are directly connected to the grid. Further details about the mathematical models can be found in [18].

\section{AC/DC/AC converter}

As illustrated in Figure 2, the $\mathrm{AC} / \mathrm{DC} / \mathrm{AC}$ converter is divided into two components: the rotor-side converter (Crot) and the grid-side converter $(\mathrm{Cgrid})$. Both are voltage-sourced converters that use IGBTs to synthesize an AC voltage from a DC voltage source. This DC voltage source is represented by a capacitor which is connected on the DC side. Essentially, the Crot converter controls the real and reactive power production of the induction machine, and the Cgrid controls the DC-link voltage and the reactive power absorbed from the grid by the converter [19]. The conventional control mechanism for these DFIG converters is based upon the decoupled d-q vector control concept, detailed in [20].

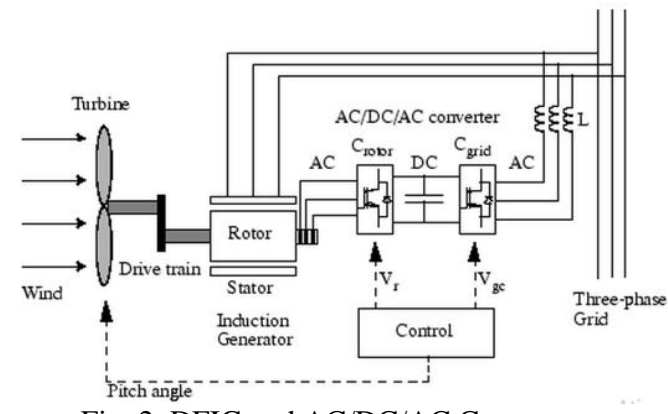

Fig. 2. DFIG and AC/DC/AC Converter

\section{Rotor-side converter control}

Stator-flux oriented control is adopted in the control scheme where the d-axis is aligned with the stator flux space vector. Reference [21] gives detailed modeling information about the Crot control. Using simplifications provided, equations (2) and (3) show that the q-axis component of the rotor current can control the generator active power, and the rotor 
d-axis current component can control directly the generator reactive power.

$$
\begin{gathered}
P_{S}=-\frac{3}{2} \frac{L_{m}}{L_{s}} v_{q s} i_{q r} \\
Q_{S}=\frac{3}{2} \frac{L_{m}}{L_{s}} v_{q s}\left(i_{m s}-i_{d r}\right)
\end{gathered}
$$

The control of the generated active power is given by the following strategy, presented in Figure 3.

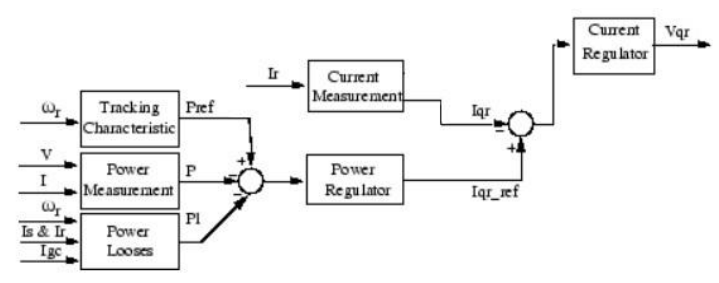

Fig. 3. Active Power Control - (Rotor-side control)

The electrical output power is measured at the wind power system terminals and it is added to the total power losses which include mechanical and electrical ones. This sum is compared with the reference power obtained from the turbine tracking characteristic curve, discussed in section $3 A$. A Proportional-Integral (PI) regulator is implemented to reduce the power error to zero, and its output is the reference rotor current Iqr_ref. Finally, by means of a current regulator, Iqr_ref is transformed into Vqr reference and it is injected into the DFIG rotor by the rotor-side converter.

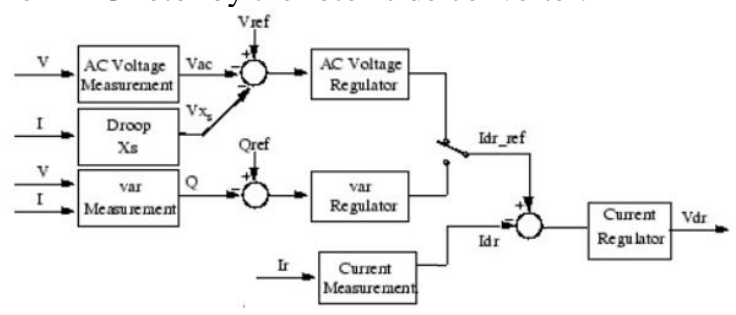

Fig 4. Reactive and Voltage Control (Rotor-side control)

The control strategy of the Crot can also control either the voltage or the reactive power at grid terminals. PI regulators are used as for the active power control. According to Figure 4, AC voltage regulation or reactive regulation (var regulation) control can be selected to have the d-axis reference current, Idr. Consequently, a current regulator is used to regulate the actual Idr component to its reference value. Its output is the d-axis voltage $\mathrm{Vdr}$, which will be injected into the rotor by the Crot [17]. When operated in voltage regulation mode, the wind turbine implements the following V-I characteristic, illustrated in Figure 5:

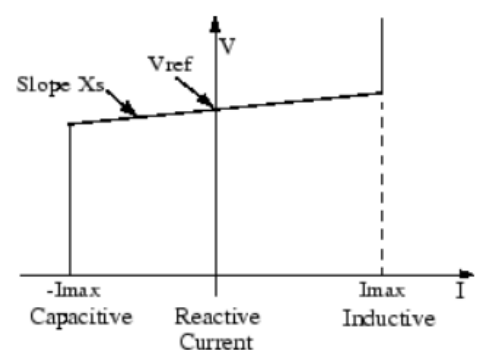

Fig. 5. V-I characteristic
The terminal voltage is regulated at the reference voltage Vref when the reactive current stays within the maximum current values (-Imax and Imax) imposed by the converter rating. The Matlab model also implements a voltage droop that varies between $1 \%$ and $4 \%$ at maximum reactive power output [17]. In this study, a $2 \%$ drop was used for the simulations.

\section{E. Grid-side converter control}

The Cgrid control is illustrated in Figure 6. The main function of the Cgrid is to maintain the DC link voltage regulated regardless of the rotor power flow.

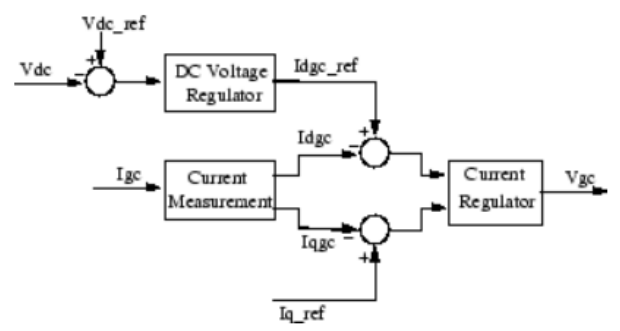

Fig. 6. Grid-side control

In addition, it allows generation or absorption of reactive power. It is worth pointing out that all converter control parameters can be found in the reference [17].

\section{F. Electrical Network}

The electrical power system single-line diagram is shown in Figure 7.

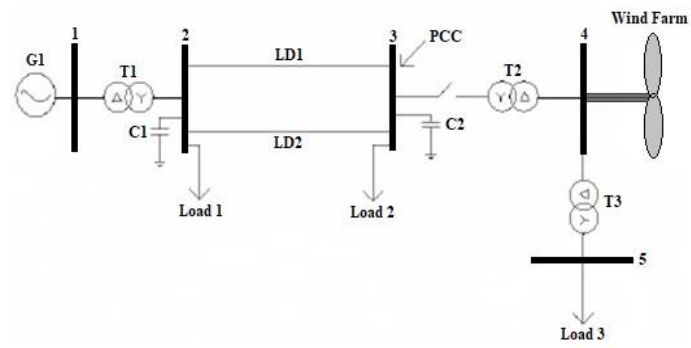

Fig. 7. Electrical Network

In this network, the point of common coupling (PCC) is represented by busbar 3. This busbar separates the distribution network and the independent energy producer which uses the wind power generation. The distribution system is represented by the elements arranged on the left side of busbar 3 . It consists of an infinite busbar (busbar 1), two $15 \mathrm{~km}$ distribution lines, a constant power load and a capacitor bank connected to busbar 2 and 3. On the other side, the independent energy producer is represented by a $9 \mathrm{MW}$ wind farm, consisting of six $1.5 \mathrm{MW}$ wind turbines, and a local load represented by a $1.68 \mathrm{MW}$ induction motor and a $200 \mathrm{KW}$ resistive load connected at busbar 5 . The data related to the distribution system are given in Table I.

\begin{tabular}{|c|c|}
\hline $\begin{array}{l}1 \text { - V ph-ph; frequency; nominal } \\
\text { power }\end{array}$ & 11.4KV; 60Hz; 2500MVA \\
\hline $\begin{array}{l}\text { T1 - Configuration; nominal } \\
\text { power; frequency; V1 ph-ph; R1; } \\
\text { L1; V2 ph-ph; R2'; L2'; Rm; Lm }\end{array}$ & $\begin{array}{l}\text { Delta/Y; 30MVA; 60Hz; } 11.4 \mathrm{KV} \text {; } \\
0.00267 \mathrm{pu} ; 0.08 \mathrm{pu} ; 13.8 \mathrm{KV} ; \\
0.00267 \mathrm{pu} ; 0.08 \mathrm{pu} ; 500 \mathrm{pu} ; 500 \mathrm{pu}\end{array}$ \\
\hline $\begin{array}{l}\text { T2 - Configuration; Nominal } \\
\text { power; frequency; V1 ph-ph; R1; } \\
\text { L1; V2 ph-ph; R2'; L2'; Rm; Lm }\end{array}$ & $\begin{array}{c}\text { Y/Delta; 12MVA; 60Hz; } 13.8 \mathrm{KV} \text {; } \\
0.00267 \mathrm{pu} ; 0.08 \mathrm{pu} ; 575 \mathrm{~V} ; \\
0.00267 \mathrm{pu} ; 0.08 \mathrm{pu} ; 500 \mathrm{pu} ; 500 \mathrm{pu}\end{array}$ \\
\hline $\begin{array}{l}\text { T3 - Configuration; Nominal } \\
\text { power; frequency; V1 ph-ph; R1; }\end{array}$ & $\begin{array}{l}\text { Delta/Y; 2.5MVA; 60Hz; 575V; } \\
\text { 0.001333pu; 0.04pu; } 2.3 \mathrm{KV}\end{array}$ \\
\hline
\end{tabular}

Table I - Electrical Network Parameters 


\begin{tabular}{|c|c|}
\hline L1; V2 ph-ph; R2'; L2'; Rm; Lm & $\begin{array}{l}0.001333 \mathrm{pu} ; 0.04 \mathrm{pu} ; 500 \mathrm{pu} ; \\
500 \mathrm{pu}\end{array}$ \\
\hline $\begin{array}{l}\mathrm{C} 1 \text { - Configuration; Nominal } \\
\text { power; V1 ph-ph }\end{array}$ & $\mathrm{Y}$ (grounded); 5MVAr; $13.8 \mathrm{KV}$ \\
\hline $\begin{array}{l}\mathrm{C} 2 \text { - Configuration; Nominal } \\
\text { power; V1 ph-ph }\end{array}$ & $\mathrm{Y}$ (grounded); 8MVAr; $13.8 \mathrm{KV}$ \\
\hline $\begin{array}{l}\text { Load } 1 \text { and Load } 2 \text { - } \\
\text { Configuration; Nominal power; } \\
\text { V1 ph-ph; Power factor }\end{array}$ & $\begin{array}{l}\text { Y (grounded); 12.5MVA; } \\
13.8 \mathrm{KV} ; 0,92 \text { inductive }\end{array}$ \\
\hline $\begin{array}{l}\text { Load } 3 \text { - MOTOR (Rotor type; } \\
\text { Nominal power; frequency; V ph- } \\
\text { ph; Rs; Ls; Rr'; Rr'; Lm; pole } \\
\text { pairs; friction factor; inertia } \\
\text { constant) / Resistive Load } \\
\text { (Configuration; Nominal power; } \\
\text { V1 ph-ph; Power factor) }\end{array}$ & $\begin{array}{c}\text { (Squirrel-cage; 1.80MVA; 60Hz; } \\
2.3 \mathrm{KV} ; 0.0092 \mathrm{pu} ; 0.0717 \mathrm{pu} ; \\
0.007 \mathrm{pu} ; 0.0717 \mathrm{pu} ; 4.14 \mathrm{pu} ; 2 ; 0 ; \\
0.5 \mathrm{~s}) /(\mathrm{Y} ; 200 \mathrm{KW} ; 2.3 \mathrm{KV})\end{array}$ \\
\hline $\begin{array}{l}\text { LD1 and LD2 - Voltage; R; Xl; } \\
\text { V1 ph-ph; Length }\end{array}$ & $\begin{array}{c}15 \mathrm{KV} ; 0,4374 \Omega / \mathrm{Km} ; 0,524 \\
\Omega / \mathrm{Km} ; 15 \mathrm{Km}\end{array}$ \\
\hline
\end{tabular}

\section{Case study}

Aiming to analyze the dynamic response of the power system, this topic presents the results, making a critical and qualitative analysis of the responses considering both topologies considered in this work: Voltage control and reactive power control with reactive power reference set to 0 (Unity power factor). The studies were developed by applying an instantaneous voltage sag Type A, at busbar 1 . From this event, it was analyzed the voltage profile at PCC (Busbar 3); active and reactive power from the DFIG wind turbines; voltage at DC link and wind turbine speed.

Table II shows a summary of steady-state response of the system for reference of studies. The response of wind turbine is based on the specifications defined in [17]. It can be observed that the steady state voltage is in accordance with the Brazilian recommended limits $(0,95-1.05 \mathrm{pu})$.

Table II - Steady state response of system

\begin{tabular}{ccc}
\hline & $\begin{array}{c}\text { DFIG with Unity } \\
\text { Power Factor }\end{array}$ & $\begin{array}{c}\text { DFIG with Voltage } \\
\text { Control }\end{array}$ \\
\hline PCC voltage & $1.029 \mathrm{pu}$ & $1.0 \mathrm{pu}$ \\
\hline Reactive Power & $0.09 \mathrm{MVar}$ & $-0.9 \mathrm{MVar}$ \\
\hline Active Power & $4.54 \mathrm{MW}$ & $4.54 \mathrm{MW}$ \\
\hline DC Link voltage & $1200 \mathrm{~V}$ & $1200 \mathrm{~V}$ \\
\hline Turbine Speed & $1.2 \mathrm{pu}$ & $1.2 \mathrm{pu}$ \\
\hline $\begin{array}{c}\text { Slack Bus Active } \\
\text { Power }\end{array}$ & $20.46 \mathrm{MW}$ & $20.46 \mathrm{MW}$
\end{tabular}

Considering the event, it was applied a voltage sag of $0.15 \mathrm{pu}$ in the three phases of busbar 1 , starting at $\mathrm{t}=5 \mathrm{~s}$ with duration of 15 cycles. Such contingency is classified as an instantaneous voltage sag Type A. Figure 8 illustrates the voltage at PCC for the voltage and reactive power control.

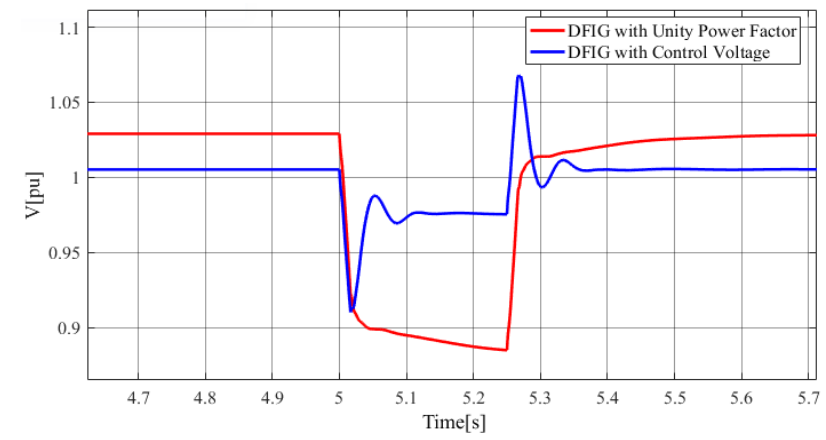

Fig.8. Voltage at PCC (busbar 3)
By analyzing the reactive power control, it can be observed that the voltage level at PCC reached $0.88 \mathrm{pu}$, which can damage various voltage sensitive devices largely employed in industrial systems, such as programmable logic controllers, power contactors, control relays, adjustable speed drives (ASD), etc. It is well known, among all power quality phenomenon, voltage sags are one of the main issues for the industry sector customers due to high economic and technical impact [22]. It is worthwhile to highlight that each electronic device has its voltage sag susceptibility. Therefore, a curve was adopted by Information Technology Industry (ITI), formally known as the Computer \& Business Equipment Manufacturers Association, (CBEMA). The ITI curve, Figure 9, describes an $\mathrm{AC}$ input voltage envelope which can typically be tolerated by most information technology (IT) equipment. Based on that, it is necessary methodologies to mitigate the effects of voltage sag in such a way to protect those sensitive loads connected at PCC. There are various systems for protecting industrial processes against voltage sags, such as Flywheel and Motor-Generator (MG), Uninterruptible Power Supply (UPS), Dynamic Voltage Restorer (DVR), STATCOM, etc.

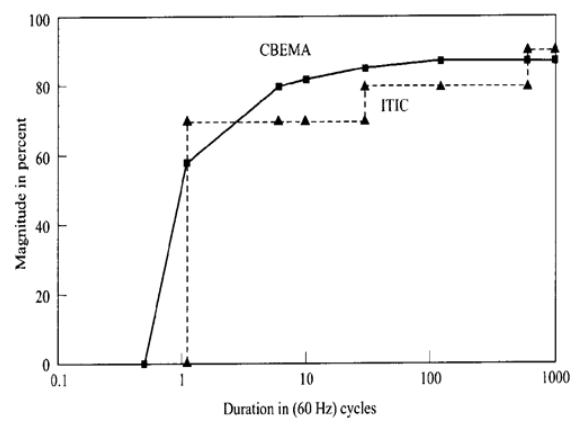

Fig. 9. ITI curve.

By analyzing the curve of voltage control in Figure 8, at the moment of voltage sag, the voltage reduces to $0.91 \mathrm{pu}$. Contrary to the voltage sag at PCC with the reactive power control, it is quite likely that this voltage level will not lead to the disruption of manufacturing processes. In addition, it can be stated that after voltage restoration, as there is a lower discharge of capacitor due to the voltage control, the impact of the transient current at DC link of the capacitor is therefore smaller. It is important to mention that induction motors are started by ASD, which have a capacitor at DC link. Figure 10 highlights the effect of a voltage sag in the current response for the capacitor at DC link of an ASD [22].

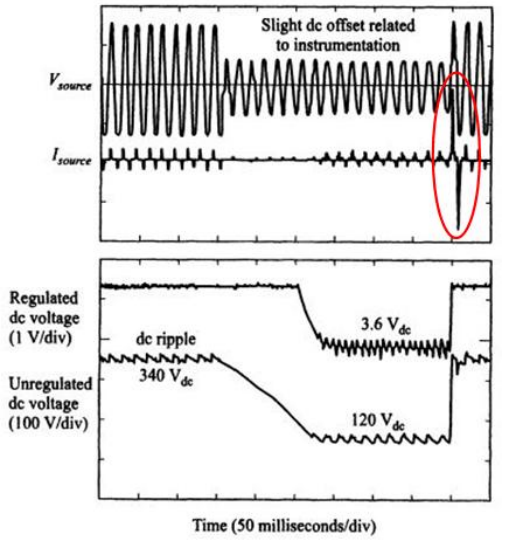

Fig. 10. Voltage sag effect on an ASD DC link 
It can still be observed from Figure 8 that with voltage control, there is an instantaneous voltage rise to almost $1.07 \mathrm{pu}$, immediately after the event. Figure 11 can explain this scenario. This figure shows a reactive power rise caused by the voltage control, which aims to restore the voltage level for the previously adjusted value. During the event, the reactive power from the wind turbine is $4 \mathrm{MVAr}$, which contributes therefore for a better voltage level. On the other hand, by looking the result related to the reactive power control, as it does not generate an expressive reactive power, the voltage level at PCC is lower than $0.9 \mathrm{pu}$.

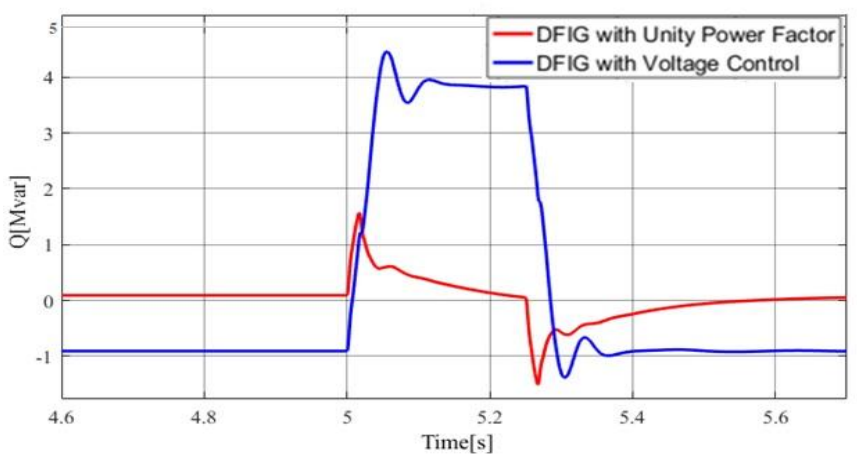

Fig. 11. Reactive power from wind power system.

The grid-side converter controller aims to keep the voltage of DC link equal to reference level in such a way to provide active power to the grid. Additionally, as required by some specifications, this controller is projected for alloying exchange of reactive power between the converter and the grid. The active power supplied to the system $\mathrm{P}_{\text {Sgrid }}$ can be obtained by the dynamic analysis at DC link, which is expressed by (4). Figure 12 illustrates the power flow at DC link.

$$
P_{C}=P_{\text {Sgen }}-\mathrm{P}_{\text {Sgrid }}
$$

Where $P_{C}$ is the active power through the capacitor of DC link; $P_{\text {Sgen }}$ is the active power from the power supply and $P_{\text {Sgrid }}$ is the active power from the DC link to the grid [23].

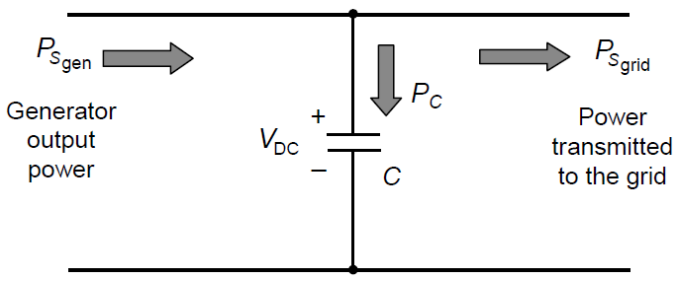

Fig. 12. Power flow at DC link.

Based on that, Figures 13 and 14 present, respectively, the active power supplied to the grid and the voltage at the DC link by considering both control methodologies. At moment of the event, the wind turbine views the voltage sag as an increase of load in the power system. From Figure 13 it can be observed a momentary rise of active power supplied. It can be seen that the active power attains $5.25 \mathrm{MW}$. In addition, at this instant, the converter control in grid side operates to meet the active power request. Therefore, as illustrated in Figure 14, it leads to a voltage rise at DC link.

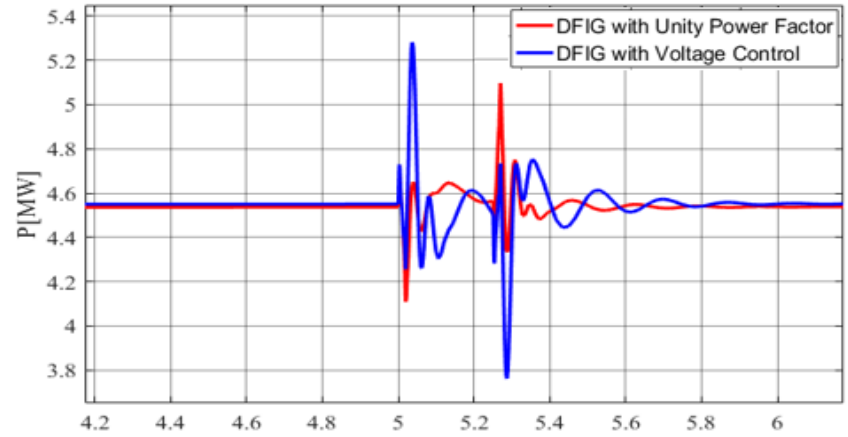

Fig. 13. Active power from wind power system.

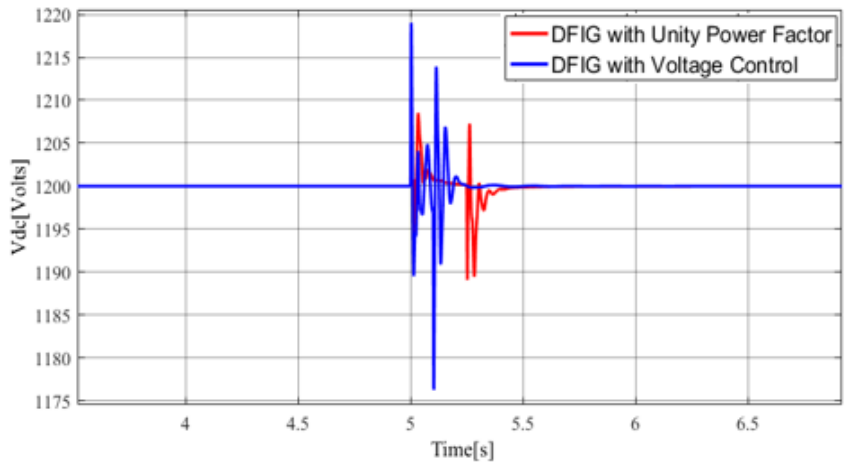

Fig. 14. Voltage at DC link.

It is important to mention the contribution to the transient stability when the voltage control is adopted. From this topology, the wind turbine increases the reactive power supplied, improves the voltage profile and it contributes therefore to the reduction of power angle excursion. The equations presented in (5) and (6) can explain the power system stability.

$$
\begin{gathered}
\delta=\frac{P_{\text {Sgrid }} \cdot X_{\text {grid }}}{V_{S} \cdot V_{R}} \\
\frac{d^{2} \delta}{d t^{2}}=\frac{\omega}{2 H} \cdot\left(P_{m}-P_{e}\right)
\end{gathered}
$$

Where $\delta$ is the rotor angle; $X_{\text {grid }}$ is the equivalent reactance; $V_{S}$ is the grid voltage; $V_{R}$ is the reference voltage; $d^{2} \delta / d t^{2}$ is angular acceleration; $\omega$ is the angular velocity; $H$ is the inertia constant; $P_{m}$ is the mechanical power and $P_{e}$ is the electrical power.

Due to the event, the wind turbine views a voltage sag Type A (three-phase short circuit), which leads to power system instability. Aiming to restore the power system stability, there is a rising trend of power angle [22]. Then, in addition, the mechanical power becomes greater than the electrical one, producing, therefore, a positive acceleration and speed rise of the turbine. However, there is a high electrical distance between the point of fault and the connection of DG. Then, the voltage sag at the busbar, where is connected the DG, is not so significant. This fact with the slow response of mechanical system leads to a negligible speed rise, as can be seen in Figure 15. Then, it can be concluded that the inertia machine is an important factor to consider in the operation and studies of grid connection of DG. A high moment of inertia of the rotor mass is less sensitive to transient oscillations. 


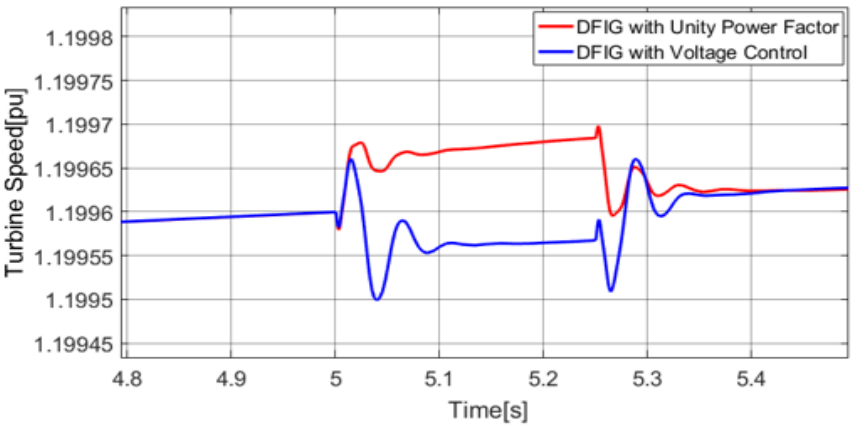

Fig. 15. Wind Turbine Speed

\section{Conclusion}

It is observed, in this paper, a comparative analysis of two DFIG control strategies provided by Matlab/Simulink. In this way, a voltage sag Type A was applied to the distributed system, and the voltage profile response was observed in front of voltage and reactive power control (with null reactive reference).

By operating the wind generators with voltage control, an improvement of the PCC voltage was observed, which leads to the safe operation of sensitive devices to voltage sags. In addition, it was shown that this control strategy contributes to keeping the transient stability. Since it causes an increase in the voltage at PCC, this control strategy contributes to the reduction of the power angle excursion. On the other hand, subsequently the contingency event, it was identified a high voltage at PCC caused by the operation of such control, which can damage the DC link converter. Furthermore, the active power oscillation may result in the actuation of the power protection relay by the active power peak observed after the applied contingency.

It is noted that further studies should be developed in order to obtain an optimum control to be applied to on-grid systems since the best control strategy for a specific contingency may not be suitable for another one.

\section{References}

[1] Famecos. Wind energy is Option for Distributed Generation. 2013. PUC R Grande do Sul. Accessed on September 10, 2017, in http://eusoufamecos.net/editorialj/eolica. $\quad\{\mathrm{In}$ Portuguese

[2] ANEEL National Electric Energy Agency (2013). Normative Resolution $n^{o}$ 482. Access on September 10, 2017, in http://www.aneel.gov.br/area.cfm?idArea $=757 \& i d P e r f i l=2 .\{$ In Portuguese

[3] W. Freitas, A. M. França, J. C. M. Vieira Jr., L. C. P. da Silva, "Comparative Analysis Between Synchronous and Squirrel Cage Induction Generators for Distributed Generation Applications". IEEE Trans. Power Systems, vol. 21, NO.1, FEBRUARY 2006.

[4] Global Wind Energy Council. Global Wind Report- Annual Market Update 2016. Accessed on September 10, 2017, in http://gwec.net/global-figures/graphs/.

[5] J. R. C. Almeida, M. J. B. B. Davi, C. B. Santos, F. A. M. Moura, J. R. Camacho, "Review of Technical Requirements for Brazilian Distribution Companies for the Integration of Distributed Generators - A Comparative Analysis on The Perspective of IEEE - STD 1547-2”, International Conference on Renewable Energies and Power Quality Journal, vol.13, 2015.
[6] C. J. Mozina, "Impact of Green Power Distributed Generation". IEEE Industry Application Magazine, vol. 16, NO.4, JULY 2010.

[7] European Commission. JRC Wind Energy Status Report 2016. Accessed on September 10, 2017, in https://setis.ec.europa.eu/sites/default/files/reports/wind_energ y_st tus_report_2016.pdf.

[8] B. Simpson, H. Simpson, X. Zhou. "Summary on the development of wind generators", in the International Conference on Mechatronics and Automation, 2017.

[9] F. Blaabjerg, Z. Chen. "Power Electronics for Modern Wind Turbines", Morgan and Claypool Synthesis Digital Library, JUNE, 2006.

[10] A. Choroq, N. Tampu, Alvarado J. "Modeling a DFIG based wind system for unbalanced grid voltage condition", in the $19^{\text {th }}$ International Conference on Intelligent System Application to Power Systems, 2017.

[11]D. Ochoa, S. Martinez. "Fast-frequency response provided by DFIG-Wind Turbines and its impact on the grid". IEEE Trans. Power Systems, vol. 32, NO.5, DECEMBER 2016.

[12] National Renewable Energy Laboratory. Harmonics in a Wind Power Plant. Accessed on September 19, 2017, in https://www.nrel.gov/docs/fy15osti/63588.pdf.

[13]M. Debouza, A. Al-Durra, S. Muyeen. "Experimental validation of a DFIG based current harmonics mitigation technique”, in the IEEE Industry Applications Society Annual Meeting, 2017.

[14]X. Zhang, X. Cao, W. Wang, C. Yun, "Fault Ride-Through Study of Wind Turbines". Journal of Power and Energy Engineering, vol. 32, NO.5, OCTOBER 2013.

[15] M. Wang, W. Xu, H. Jia. "A New Method for DFIG Fault Ride Through Using Resistance and Capacity Crowbar Circuit", in the IEEE International Conference on Industrial Technology, 2013.

[16]B. Gong, D. Xu, H. Wu. "Cost-Effective Method for DFIG fault ride-through during symmetrical voltage dip", in the $36^{\text {th }}$ Annual Conference on IEEE Industrial Electronics Society, 2010.

[17]MathWorks Documentation). Normative. Wind Turbine Doubly-Fed Induction Generator (Phasor Type). Accessed on August 3, 2017, in https://www.mathworks.com/help/ physmod/sps/powersys/ref/windturbinedoublyfedinductiongene ratorphasortype.html

[18] T. Sow, O. Akhrif, A. F. Okou. "Control strategy ensuring the contribution of DFIG-Based wind turbines to primary and secondary frequency regulation", in the IEEE Industrial Electronics Society, 2011.

[19]A. Noubrik, L. Chrifi-Alaoui, P. Bussy. "Analysis and simulation of a 1.5MVA doubly fed wind-power in MATLAB SimPowerSystems using crowbar during power systems disturbances", in the International Conference on Communications, Computing and Control Applications, 2011.

[20] H. Misra, A. K. Jain. "Mathematical modeling and control of standalone DFIG-DC system in rotor flux reference frame”, IEEE Trans. Industrial, vol. 65, NO.5, MAY 2018.

[21] I. Esandi, X. Juankorena, J Lopez. "Alternative Protection System for wind turbines with doubly fed induction generator", in the International Conference on Power Engineering, Energy and Electrical Drives, 2009.

[22] M. H. Bollen. 2000. Understanding Power Quality Problems: Voltage Sags and Interruptions. $1^{\text {st }}$ ed. New Jersey: John Wiley\&Sons.

[23] B. Fox, D. Flynn, L. Bryans. 2014. Power System Stability and Control. $1^{\text {st }}$ ed. New York City: McGraw-Hill Professional Publishing. 